\title{
SISTEM PENDUKUNG KEPUTUSAN PENERIMA BEASISWA PPA DAN BBM MENGGUNAKAN METODE SIMPLE ADDITIVE WEIGHTING (SAW)
}

\author{
M. Safii \\ Program Studi Komputerisasi Akunatansi, AMIK Tunas Bangsa \\ Jl. Jend. Sudirman Blok A No.1-3 Pematangsiantar \\ m.safii@amiktunasbangsa.ac.id
}

\begin{abstract}
Improving Academic Achievement Scholarship (PPA) and Student Learning Aid (BBM) is one of the stimulus given to the government for students with the aim of motivating students to enhance the spirit of learning. In accordance with the program guidelines issued by the Directorate General of Higher Education must follow the principle of 3T is Right Target, Right Number and Timely. Computer Informatic Management Academy (AMIK) Tunas Bangsa Pematangsiantar is one of the private universities obtained on the scholarship quota. In accordance with the number of students currently as many as 1,400 people then the allocation of the scholarship must be selected carefully to fit the government guidelines. In this case we need a method that can support decision boosters system (DSS) in determining the grantee is using simple additive weighting method (SAW). With the basic concepts seek a weighted sum of the rating performance of each alternative on all attributes that require a decision matrix normalization process. This method can make an assessment criteria and detailed compound with a comprehensive framework considerations hierarchy process which then calculate the weights to each criterion in determining the priority recommendations of PPA and BBM scholarship recipients in accordance with the target.
\end{abstract}

Keywords: Scholarships, PPA and BBM, Selection, SPK, SAW Method

\begin{abstract}
Abstrak
Beasiswa Peningkatan Prestasi Akademik (PPA) dan Bantuan Belajar Mahasiswa (BBM) merupakan salah satu stimulus yang diberikan kepada pemerintah bagi mahasiswa dengan tujuan memotivasi mahasiswa untuk meningkatkan semangat belajar. Sesuai dengan pedoman program tersebut yang dikeluarkan oleh Direktorat Jenderal Pendidikan Tinggi harus mengikuti prinsip 3T yaitu Tepat Sasaran, Tepat Jumlah dan Tepat Waktu. Akademi Manajemen Informtika Komputer (AMIK) Tunas Bangsa Pematangsiantar merupakan salah satu Perguruan Tinggi Swasta yang memperoleh quota atas beasiswa tersebut. Sesuai dengan jumlah mahasiswa saat ini sebanyak 1.400 orang maka alokasi beasiswa tersebut harus diseleksi dengan cermat agar sesuai dengan pedoman pemerintah. Dalam hal ini dibutuhkan suatu metode yang dapat mendukung sistem pedukung keputusan (SPK) dalam menetukan penerima beasiswa tersebut yaitu menggunakan metode simple additive weighting (SAW). Dengan konsep dasar mencari penjumlahan terbobot dari rating kinerja pada setiap alternatif pada semua atribut yang membutuhkan proses normalisasi matriks keputusan. Metode ini dapat melakukan penilaian kriteria majemuk dan detail dengan suatu kerangka berpikir yang komprehensif pertimbangan proses hirarki yang kemudian dilakukan perhitungan bobot untuk masing-masing kriteria dalam menentukan prioritas rekomendasi penerima beasiswa PPA dan BBM sesuai dengan sasarannya.
\end{abstract}

Kata Kunci: Beasiswa, PPA dan BBM, Seleksi, SPK, Metode SAW

\section{PENDAHULUAN}

Setiap warga negara berhak mendapatkan pengajaran yang dicantumkan dalam Pasal 31 (1) Undang-Undang Dasar 1945. Berdasarkan pasal tersebut, maka Pemerintah dan pemerintah daerah wajib memberikan layanan dan kemudahan, serta menjamin 
terselenggaranya pendidikan yang bermutu bagi setiap warga negara tanpa diskriminasi, dan masyarakat berkewajiban memberikan dukungan sumber daya dalam penyelenggaraan pendidikan. Untuk menyelenggarakan pendidikan yang bermutu diperlukan biaya yang cukup besar. Oleh karena itu bagi setiap peserta didik pada setiap satuan pendidikan berhak mendapatkan biaya pendidikan bagi mereka yang orang tuanya tidak mampu membiayai pendidikannya, dan berhak mendapatkan beasiswa bagi mereka yang berprestasi. Berdasarkan Undang-undang dan Peraturan Pemerintah, maka Pemerintah melalui Direktorat Jenderal Pendidikan Tinggi Kementerian Pendidikan Nasional, mengupayakan pemberian bantuan biaya pendidikan bagi mahasiswa yang orang tua/walinya kurang mampu membiayai pendidikan, dalam bentuk Bantuan Biaya Mahasiswa (BBM) dan Beasiswa bagi mahasiswa berprestasi dalam bentuk Beasiswa Peningkatan Prestasi Akademik (PPA)[1].

Pemberian beasiswa ini harus mengacu pada pedoman yang dikeluarkan oleh Direktorat Jenderal Pendidikan Tinggi yaitu prinsip 3T : Tepat Sasaran, Tepat Jumlah dan Tepat Waktu. Dalam hal ini dibutuhkan suatu sistem yang dapat membantu membuat keputusan, salah satunya menggunakan metode simple additive weighting. Metode SAW (simple additive weighting) digunakan untuk menentukan nilai bobot untuk setiap attribut dengan kreteria-kreteria penilaian yang telah ditentukan [6], kemudian dilanjutkan dengan proses penyeleksian sebagai tahap seleksi yang berhak menerima bantuan beasiswa PPA dan BBM. [2]

\section{METODE PENELITIAN}

\subsection{Sistem Pendukung Keputusan}

Manusia merupakan bagian dari alam karena hidupnya yang tidak terlepas dari alam. Proses kehidupan manusia merupakan unsur yang semakin lama semakin mendominasi unsur-unsur lainnya di alam. Hal ini disebabkan karena manusia dibekali kemampuan-kemampuan untuk bisa berkembang. Segala proses yang terjadi di sekelilingnya dan dalam dirinya dirasakan dan diamatinya dengan menggunakan semua indera yang dimilikinya, dipikirkannya lalu berbuat dan bertindak. Dalam menghadapi segala proses yang terjadi disekelilingnya dan di dalam dirinya, hampir setiap saat manusia membuat atau mengambil keputusan dan melaksanakannya. Hal ini dilandasi dengan asumsi bahwa segala tindakan dilakukan secara sadar merupakan pencerminan hasil proses pengambilan keputusan dalam pikirannya, sehingga sebenarnya manusia sudah sangat terbiasa dalam membuat keputusan[3].

\subsection{Konsep Dasar Sistem Pendukung Keputusan}

Sistem penunjang keputusan (Decision Support Systems - DSS) sebagai sistem yang digunakan untuk mendukung dan membantu pihak manajemen melakukan pengambilan keputusan pada kondisi semi terstruktur dan tidak terstruktur [4]. Konsep Decision Support System(DSS) pertama kali diperkenalkan awal tahun 1970-an oleh Michael Scott Morton, yang selanjutnya dikenal dengan istilah Management Decision System. Konsep Decision Support System(DSS) merupakan sebuah sistem interaktif berbasis komputer yang membantu pembuatan keputusan memanfaatkan data dan model untuk menyelesaikan masalah yang bersifat tidak terstruktur dan semi terstruktur. Decision Support System(DSS) dirancang untuk menunjang seluruh tahapan pembuatan keputusan, yang dimulai dari tahapan mengidentifikasi masalah, memilih 
data yang relevan, menentukan pendekatan yang digunakan dalam proses pembuatan keputusan sampai pada kegiatan mengevaluasi pemilihan alternatif.

\subsection{Metode Simple Additive Weighting(Saw)}

Metode SAW merupakan metode yang juga dikenal dengan metode penjumlahan berbobot [5]. Konsep dasar metode SAW adalah mencari penjumlahan terbobot dari rating kinerja pada setiap alternatif pada semua atribut (Fishburn, 1967) (MacCrimmon, 1968). Metode SAW membutuhkan proses normalisasi matriks keputusan $(\mathrm{X})$ ke suatu skala yang dapat diperbandingkan dengan semua rating alternatif yang ada. Metode ini merupakan metode yang paling terkenal dan paling banyak digunakan dalam menghadapi situasi Multiple Attribute Decision Making (MADM). MADM itu sendiri merupakan suatu metode yang digunakan untuk mencari alternatif optimal dari sejumlah alternatif dengan kriteria tertentu.

Beberapa tahapan untuk menyelesaikan suatu kasus menggunakan metode SAW adalah [7]:

1. Menentukan kriteria-kriteria yang akan dijadikan acuan dalam pengambilan keputusan, yaitu Ci.

2. Menentukan rating kecocokan setiap alternatif pada setiap kriteria

3. Membuat matriks keputusan berdasarkan kriteria(Ci), kemudian melakukan normalisasi matriks berdasarkan persamaan yang disesuaikan dengan jenis atribut (atribut keuntungan ataupun atribut biaya) sehingga diperoleh matriks ternormalisasi R.

4. Hasil akhir diperoleh dari proses perankingan yaitu penjumlahan dari perkalian matriks ternormalisasi $\mathrm{R}$ dengan vektor bobot sehingga diperoleh nilai terbesar yang dipilih sebagai alternatif terbaik (Ai)sebagai solusi.

Formula untuk melakukan normalisasi tersebut adalah :

\begin{tabular}{|c|c|c|}
\hline \multirow{2}{*}{$\mathrm{rij}_{\mathrm{ij}}=$} & $\begin{array}{c}X_{\mathrm{ij}} \\
\text { Max Xij }\end{array}$ & Jika $\mathrm{j}$ adalah atribut keuntungan (benefit) \\
\hline & $\begin{array}{c}X_{i j} \\
\text { Min } X_{i j} \\
\end{array}$ & Jika $\mathrm{j}$ adalah atribut biaya (cost) \\
\hline
\end{tabular}

Dimana:

$\mathrm{r}_{\mathrm{ij}} \quad=$ rating kinerja ternormalisasi

$\operatorname{Max}_{\mathrm{ij}} \quad=$ nilai maksimum dari setiap baris dan kolom

$\operatorname{Min}_{\mathrm{ij}} \quad=$ nilai minimum dari setiap baris dan kolom

$\mathrm{X}_{\mathrm{ij}} \quad=$ baris dan kolom dari matriks

Dengan rij adalah rating kinerja ternormalisasi dari alternatif Ai pada atribut $\mathrm{Cj}$; $\mathrm{i}=1,2, \ldots \mathrm{m}$ dan $\mathrm{j}=1,2, \ldots, \mathrm{n}$. Nilai preferensi untuk setiap alternatif (Vi) diberikan sebagai :

$$
V i=\sum_{j=1}^{n} W_{j} r_{i j}
$$


Dimana :

$\mathrm{V}_{\mathrm{i}}=$ Nilai akhir dari alternatif

$\mathrm{w}_{\mathrm{j}}=$ Bobot yang telah ditentukan

$\mathrm{r}_{\mathrm{ij}}=$ Normalisasi matriks

Nilai Vi yang lebih besar mengindikasikan bahwa alternatif Ai lebih terpilih

\section{HASIL DAN PEMBAHASAN}

\subsection{Kriteria}

Tahap awal dari penyelesaian studi kasus ini adalah menganalisa kriteria sebagai dasar proses dilakukannya seleksi. Penentuan kriteria ini berdasarkan pedoman yang dikeluarkan oleh Kemenristek Dikti. Adapun kriteria yang digunakan adalah Gaji Orangtua (GO), Prestasi Ekskul (PE), Indeks Prestasi Kumulatif (IPK), Asal Daerah (AD) dan Absensi Mahasiswa (AM). Contoh data dari kriteria tersebut adalah sbb:

Tabel 1. Data Krteria

\begin{tabular}{|c|c|c|c|c|c|c|c|}
\hline \multirow{2}{*}{ NIM } & \multirow{2}{*}{ Nama } & Prodi & $\begin{array}{c}\text { Gaji } \\
\text { Orang } \\
\text { Tua }\end{array}$ & $\begin{array}{c}\text { Prestasi Eks. } \\
\text { Kurikuler }\end{array}$ & IPK & $\begin{array}{c}\text { Asal } \\
\text { Daerah }\end{array}$ & Absensi \\
\hline 0101 & A & MI & $3.5 j \mathrm{jt}$ & 3 & 3.5 & Kota & 90 \\
\hline 0102 & B & MI & $2.2 \mathrm{jt}$ & 4 & 3.0 & $3 \mathrm{~T}$ & 100 \\
\hline 0103 & C & MI & $4.5 j \mathrm{jt}$ & 2 & 3.8 & Kab & 90 \\
\hline 0204 & D & KA & $2.0 j t$ & 7 & 3.5 & Kota & 88 \\
\hline 0205 & E & KA & $1.5 j t$ & 8 & 4.0 & $3 T$ & 90 \\
\hline
\end{tabular}

\subsection{Pembobotan}

Pembobotan dari kriteria tersebut adalah sebagai berikut:

1. Gaji Orang Tua (GO), dibobotkan atas:

Tabel 2. Pembobotan Kriteria Gaji

\begin{tabular}{|l|l|c|}
\hline \multicolumn{1}{|c|}{ Jumlah Penghasilan } & \multicolumn{1}{c|}{ Bobot } & Nilai \\
\hline$>5.000 .000$ & Sangat Tinggi & 5 \\
\hline 4.999 .000 s.d. 3.500 .000 & Tinggi & 4 \\
\hline 3.499 .000 s.d. 2.000 .000 & Cukup & 3 \\
\hline 1.999 .000 s.d. 1.500 .000 & Rendah & 2 \\
\hline$<1.499 .000$ & Sangat Rendah & 1 \\
\hline
\end{tabular}

2. Prestasi Ekstrakurikuler (PE), dibobotkan atas:

Tabel 3. Pembobotan Prestasi Ekstrakurikuler

\begin{tabular}{|c|l|c|}
\hline Prestasi & \multicolumn{1}{|c|}{ Bobot } & Nilai \\
\hline $1-3$ & Sangat Tinggi & 5 \\
\hline $4-5$ & Tinggi & 4 \\
\hline $6-7$ & Cukup & 3 \\
\hline $8-9$ & Rendah & 2 \\
\hline 10 & Sangat Rendah & 1 \\
\hline
\end{tabular}


3. Indeks Prestasi Kumulatif (IPK), dibobotkan atas:

Tabel 4. Pembobotan IPK

\begin{tabular}{|c|l|c|}
\hline IPK & \multicolumn{1}{|c|}{ Bobot } & Nilai \\
\hline 3.6 s.d 4.00 & Sangat Tinggi & 5 \\
\hline 3.5 s.d 3.0 & Tinggi & 4 \\
\hline 2.9 s.d 2.5 & Cukup & 3 \\
\hline 2.4 s.d 2.0 & Rendah & 2 \\
\hline$<1.9$ & Sangat Rendah & 1 \\
\hline
\end{tabular}

4. Asal Daerah (AD), dibobotkan atas:

Tabel 5. Pembobotan Asal Daerah

\begin{tabular}{|c|l|c|}
\hline Asal Daerah & \multicolumn{1}{|c|}{ Bobot } & Nilai \\
\hline 3T & Sangat Tinggi & 3 \\
\hline Kabupaten & Tinggi & 2 \\
\hline Kotamadya & Cukup & 1 \\
\hline
\end{tabular}

5. Absensi Mahasiswa (AM), dibobotkan atas:

Tabel 6. Pembobotan Absensi

\begin{tabular}{|c|l|c|}
\hline Absensi & \multicolumn{1}{|c|}{ Bobot } & Nilai \\
\hline 100 & Sangat Tinggi & 5 \\
\hline $99-86$ & Tinggi & 4 \\
\hline $85-70$ & Cukup & 3 \\
\hline $69-50$ & Rendah & 2 \\
\hline$<49$ & Sangat Rendah & 1 \\
\hline
\end{tabular}

\subsection{Rating}

Berdasarkan data dari kriteria diatas maka langkah berikutnya adalah membuat rating kecocokan seperti pada tabel berikut:

Tabel 7. Rating Kecocokan

\begin{tabular}{|c|c|c|c|c|c|c|c|}
\hline \multirow{2}{*}{ NIM } & \multirow{2}{*}{ Nama } & \multirow{2}{*}{ Prodi } & $\begin{array}{c}\text { Gaji } \\
\text { Orang } \\
\text { Tua }\end{array}$ & $\begin{array}{c}\text { Prestasi Eks. } \\
\text { Kurikuler }\end{array}$ & IPK & $\begin{array}{c}\text { Asal } \\
\text { Daerah }\end{array}$ & Absensi \\
\hline 0101 & A & MI & 4 & 5 & 4 & 1 & 4 \\
\hline 0102 & B & MI & 3 & 4 & 4 & 3 & 5 \\
\hline 0103 & C & MI & 4 & 5 & 5 & 2 & 4 \\
\hline 0204 & D & KA & 3 & 3 & 4 & 1 & 4 \\
\hline 0205 & E & KA & 2 & 2 & 5 & 3 & 4 \\
\hline
\end{tabular}

\subsection{Transformasi Matriks X}

Dari hasil rating kecocokan pada tabel diatas tahap berikutnya adalah menetukan nilai transformasi ke dalam matriks X

$$
X=\left[\begin{array}{lllll}
4 & 5 & 4 & 1 & 4 \\
3 & 4 & 4 & 3 & 5 \\
4 & 5 & 5 & 2 & 4 \\
3 & 3 & 4 & 1 & 4
\end{array}\right]
$$




\subsection{Nilai Bobot (W)}

Dalam memberikan nilai bobot dari kriteria dibentuk berdasarkan urutan pedoman yang berlaku sebagai berikut:

Tabel 8. Nilai Bobot $(W)$

\begin{tabular}{|c|c|c|c|c|c|}
\hline Kriteria & GO (C1) & PE (C2) & IPK (C3) & AD (C4) & AM (C5) \\
\hline Bobot & $20 \%$ & $30 \%$ & $30 \%$ & $10 \%$ & $10 \%$ \\
\hline
\end{tabular}

\subsection{Penggolongan Kriteria}

Sebelum dilakukan perhitungan Matriks $\mathrm{R}$ dilakukan penggolongan kriteria kedalam nilai benefit atau cost dan yang menjadi atribut keuntungan adalah benefit sedangkan biaya adalah cost, terlihat seperti pada tabel berikut:

Tabel 9. Penggolongan Kriteria

\begin{tabular}{|c|c|c|c|c|c|}
\hline Kriteria & GO (C1) & PE (C2) & IPK (C3) & AD (C4) & AM (C5 \\
\hline Benefit & - & $\checkmark$ & $\checkmark$ & $\checkmark$ & $\checkmark$ \\
\hline Cost & $\checkmark$ & - & - & - & - \\
\hline
\end{tabular}

\subsection{Normalisasi Matriks X}

Proses ini akan menrntukan nilai R dari masing-masing kriteria. Perhitungan normalisasinya adalah sebagai berikut:

1. Kriteria Gaji Orang tua, merupakan atribut cost sebab semakin kecil penghasilan semakin baik.

$$
\begin{aligned}
& \mathrm{R} 1,1=\frac{\min \left(\begin{array}{llll}
4 & 3 & 4 & 3
\end{array}\right)}{4}=\frac{2}{4}=0,5
\end{aligned}
$$

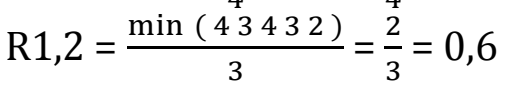

$$
\begin{aligned}
& \mathrm{R} 1,3=\frac{\min \left(\begin{array}{llll}
3 & 34 & 3 & 2
\end{array}\right)}{4}=\frac{2}{4}=0,5 \\
& \mathrm{R} 1,4=\frac{\min \left(\begin{array}{llll}
4 & 3432
\end{array}\right)}{3}=\frac{2}{3}=0,6 \\
& \mathrm{R} 1,5=\frac{\min \left(\begin{array}{llll}
4 & 3 & 4 & 3
\end{array}\right)}{2}=\frac{2}{2}=1
\end{aligned}
$$

2. Kriteria Prestasi Ekstrakurikuler, merupakan benefit sebab semakin tinggi nilai semakin baik.

$$
\begin{aligned}
& \mathrm{R} 2,1=\frac{5}{\max (54532)}=\frac{5}{5}=1 \\
& \mathrm{R} 2,2=\frac{4}{\max (54532)}=\frac{4}{5}=0,8 \\
& \mathrm{R} 2,3=\frac{5}{\max (54532)}=\frac{5}{5}=1 \\
& \mathrm{R} 2,4=\frac{3}{\max (54532)}=\frac{3}{5}=0,6 \\
& \mathrm{R} 2,5=\frac{2}{\max (54532)}=\frac{2}{5}=0,4
\end{aligned}
$$

3. Kriteria Indeks Prestasi Kumulatif (IPK), merupakan benefit sebab semakin tinggi IPK semakin baik. 


$$
\begin{aligned}
& \mathrm{R} 3,1=\frac{4}{\max (44545)}=\frac{4}{5}=0,8 \\
& \mathrm{R} 3,2=\frac{4}{\max (44545)}=\frac{4}{5}=0,8 \\
& \mathrm{R} 3,3=\frac{5}{\max (44545)}=\frac{5}{5}=1 \\
& \mathrm{R} 3,4=\frac{4}{\max (44545)}=\frac{4}{5}=0,8 \\
& \mathrm{R} 3,5=\frac{5}{\max (44545)}=\frac{5}{5}=1
\end{aligned}
$$

4. Kriteria asal daerah, merupakan benefit sebab semakin tinggi nilai semakin baik.

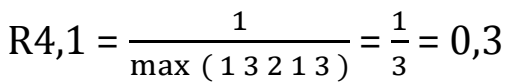

$$
\begin{aligned}
& \mathrm{R} 4,2=\frac{3}{\max \left(\begin{array}{llll}
1 & 3 & 2 & 13
\end{array}\right)}=\frac{3}{3}=1
\end{aligned}
$$

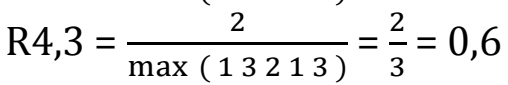

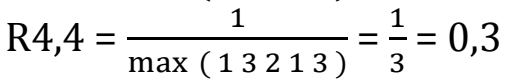

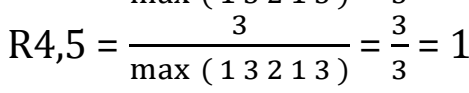

5. Kriteria Absensi, merupakan benefit sebab semakin tinggi nilai absensi akan semakin baik

$$
\begin{aligned}
& \mathrm{R} 5,1=\frac{4}{\max (45444)}=\frac{4}{5}=0,8 \\
& \mathrm{R} 5,2=\frac{5}{\max (45444)}=\frac{5}{5}=1 \\
& \mathrm{R} 5,3=\frac{4}{\max (45444)}=\frac{4}{5}=0,8 \\
& \mathrm{R} 5,4=\frac{4}{\max (45444)}=\frac{4}{5}=0,8 \\
& \mathrm{R} 5,5=\frac{4}{\max (45444)}=\frac{4}{5}=0,8
\end{aligned}
$$

Dari perhitungan masing-masing kriteria maka diperoleh matriks $\mathrm{R}$ sebagai berikut:

$$
R=\left[\begin{array}{ccccc}
0,5 & 1 & 0,8 & 0,3 & 0,8 \\
0,6 & 0,8 & 0,8 & 1 & 1 \\
0,5 & 1 & 1 & 0,6 & 0,8 \\
0,6 & 0,6 & 0,8 & 0,3 & 0,8 \\
1 & 0,4 & 1 & 1 & 0,8
\end{array}\right]
$$

\subsection{Penentuan Ranking}

Untuk mendapatkan nilai dari calon penerima beasiswa PPA dan BBM dihitung dengan menggunakan formula berikut:

$$
\mathrm{Vi}=\sum_{\mathrm{j}=1}^{\mathrm{n}} \mathrm{Wj}_{\mathrm{j}} \mathrm{rij}_{\mathrm{ij}}
$$


Dengan hasil perhitungan:

$$
\begin{aligned}
\mathrm{Vi} & =0,5(0,2)+0,6(0,3)+0,5(0,3)+0,6(0,1)+1(0,1) \\
& =0,59 \\
V i & =1(0,2)+0,8(0,3)+1(0,3)+0,6(0,1)+0,4(0,1) \\
& =0,84 \\
V i & =0,8(0,2)+0,8(0,3)+1(0,3)+0,8(0,1)+1(0,1) \\
& =0,88 \\
V i & =0,3(0,2)+1(0,3)+0,6(0,3)+0,3(0,1)+1(0,1) \\
& =0,67 \\
V i & =0,8(0,2)+1(0,3)+0,8(0,3)+0,8(0,1)+0,8(0,1) \\
& =0,86
\end{aligned}
$$

Dari hasil pengolahan formula $\mathrm{Vi}$, maka masing-masing calon penerima beasiswa dapat dirankingkan sebagai berikut:

Tabel 10. Pe-rankingan

\begin{tabular}{|c|c|c|c|}
\hline NIM & Nama & Nilai Vi & Ranking \\
\hline 0101 & A & 0,59 & 5 \\
\hline 0102 & B & 0,84 & 3 \\
\hline 0103 & C & 0,88 & 1 \\
\hline 0204 & D & 0,67 & 4 \\
\hline 0205 & E & 0,86 & 2 \\
\hline
\end{tabular}

Berdasarkan proses pe-ranking-an diatas maka dsisimpulkan bahwa prioritas penerima beasiswa PPA dan BBM adalah sebagai berikut:

Tabel 11. Tabel Penerima

\begin{tabular}{|c|c|l|c|}
\hline NIM & Nama & Nilai Vi & Ranking \\
\hline 0103 & C & 0,88 & 1 \\
\hline 0205 & E & 0,86 & 2 \\
\hline 0102 & B & 0,84 & 3 \\
\hline 0204 & D & 0,67 & 4 \\
\hline 0101 & A & 0,59 & 5 \\
\hline
\end{tabular}




\section{SIMPULAN}

Dari penelitian yang dilakukan berdasarkan peraturan Pemerintah yang dikeluarkan oleh Kemenristek Dikti yang diuji coba dengan Sistem Pendukung Keputusan menggunakan algoritma simple additive weighting (SAW) dapat disimpulkan sebagai berikut:

a. Penelitian ini dapat dijadikan rekomendasi untuk menjalankan pedoman penerima beasiswa PPA dan BBM bagi perguruan tinggi

b. Penelitian ini merupakan salah satu implementasi keilmuan yang dapat memecahkan masalah seleksi dari berbagai kasus.

c. Penerapan Metode simple additive weighting (SAW) menghasilkan nilai dari masing-masing kriteria berupa pembobotan, rating dan ranking.

d. Diharapkan penelitian ini dapat dimanfaatkan bagi perguruan tinggi sehingga dapat membantu manajemen pendidikan dalam membuat keputusan pada proses seleksi penerima beasiswa PPA dan BBM bagi seluruh mahasiswa. e.

\section{DATAR PUSTAKA:}

[1] belmawa.ristekdikti.go.id

[2] Yohana Dewi Lulu W. Rani Maya Sari, Heni Rachmawati. Sistem Pendukung Keputusan Penentuan Karyawan Terbaik Menggunakan Metode Saw (Simple Additive Weighting) Studi Kasus Pt. Pertamina RU II Dumai. Sistem Informasi, Politeknik Caltex Riau. 2014

[3] Dadan Umar Daihani, "Komputerisasi Pengambilan Keputusan", Elex Media Komputindo.Jakarta, 2001

[4] Kusrini. 2007. Konsep dan Aplikasi Sistem Pendukung Keputusan. Penerbit Andi,. Yogyakarta

[5] Kusumadewi, Sri \& Purnomo H. 2007. Aplikasi Logika Fuzzy untuk Pendukung Keputusan. Yogyakarta: Graha Ilmu

[6] Alif Wahyu Oktaputra, Dr., Ir Edi Noersasongko,M.Kom. Sistem Pendukung Keputusan Kelayakan Pemberian Kredit Motor Menggunakan Metode Simple Additive Weighting Pada Perusahaan Leasing Hd Finance. STMIK Budi Darma Medan.2015

[7] Setiaji, Pratomo, "Sistem Pendukung Keputusan Dengan Metode Simple Additive Weighting," Jurnal Simetris vol.1 no.1 Universitas Muria Kudus, Kudus.2012 